\title{
Interfacial Properties of Polyethylene Glycol/Vinyltriethoxysilane (PEG/VTES) Copolymers and their Application to Stain Resistance
}

\author{
Yin-Chun Chao $\cdot$ Shuenn-Kung Su • \\ Ya-Wun Lin · Wan-Ting Hsu $\cdot$ Kuo-Shien Huang
}

Received: 27 July 2011 / Accepted: 11 October 2011 / Published online: 1 November 2011

(C) The Author(s) 2011. This article is published with open access at Springerlink.com

\begin{abstract}
In this study, polyethylene glycol (PEG) and vinyltriethoxysilane (VTES) were used in different proportions to produce a series of PEG-VTES copolymers. The copolymer molecular structures were confirmed by FTIR spectroscopy. In addition, their surface activities were evaluated by evaluating the surface tension, contact angle, and foaming properties. The results showed that these surfactants exhibited excellent surface activities and wetting power, as well as low foaming. Consequently, the application of a series of PEG/VTES copolymers can make cotton fabrics stain resistant.
\end{abstract}

Keywords Stain resistance - Polyethylene glycol . Vinyltriethoxysilane $\cdot$ Copolymer $\cdot$ Surface activity

\section{Introduction}

As technology develops, public demand for fabrics has surpassed fundamental requirements to include both style and function. Therefore, multifunctional, compound woven products have attracted attention [1]. One example is stainresistant functional textiles. Woven products are often stained; if dark and light fabrics are washed together, the light-colored fabric is stained. At present, stain-resistance engineering primarily modifies the fibers or finishes and processes fabrics functionally. The addition of stain-

Y.-C. Chao - S.-K. Su

Department of Materials Science and Engineering, National

Taiwan University and Technology, Taipei 106, Taiwan

Y.-W. Lin · W.-T. Hsu - K.-S. Huang ( $₫)$

Department of Materials Engineering, Kun Shan University,

Yung Kang, Tainan 71003, Taiwan

e-mail: hks45421@ms42.hinet.net resistant products to fabric washing is seldom performed; thus, the development of functional finishing and processing agents is urgently required $[2,3]$.

Polyethylene glycol (PEG; molecular formula $\mathrm{H}-(\mathrm{O}$ $\left.\left.-\mathrm{CH}_{2}-\mathrm{CH}_{2}\right)_{\mathrm{n}}-\mathrm{OH}\right)$ consists of a linear chain structure composed of repeating ethylene oxide groups possessing a hydroxyl group at both ends. PEG is a glycol non-ionic agent in which the oxygen atoms are hydrophilic, while the $-\mathrm{CH}_{2}-\mathrm{CH}_{2}-$ groups display lipophilicity. The amphipathic copolymers with PEG can form spontaneous supermolecules in solvents. Polyethylene glycol covers the hydrophobic core as a hydrophilic chain; thus, PEG is soluble in water and most organic solvents [4-6]. PEG displays many beneficial physical and biological properties, including hydrophilicity, dissolubility, non-toxicity, and non-immunogenicity. Additionally, PEG does not cause rejection reactions and has been approved by the US FDA to be used in drug and food products due to its excellent biocompatibility. It is widely used in the pharmaceutical industry, agriculture, food handling, biological and material sciences, and chemical engineering fields [7-11].

Vinyltriethoxysilane (VTES) is a silane containing unsaturated double bonds [12]. VTES dissolves in alcohol, ethers, and benzene but is insoluble in water. VTES hydrolyzes in water and gradually polymerizes into macromolecules, thus resulting in a viscosity increase. The molecular structure of VTES contains an $-\mathrm{OC}_{2} \mathrm{H}_{5}$ reactive group that can combine with inorganic materials, such as glass, cement, and metals, and a $-\mathrm{CH}=\mathrm{CH}_{2}$ reactive group that can combine with organic materials, such as synthetic resins. VTES can also couple the two material interfaces, improving the performance of composite materials by increasing their bonding strength [13]. Olefin homo- or copolymers can be cross-linked with VTES [13, 14], including low-density polyethylene (LDPE), high-density 
polyethylene (HDPE), polypropylene (PP), polyvinyl chloride (PVC), chlorinated polyethylene (CPE), ethylene propylene rubber (EPR), ethylene vinyl acetate (EVA), and other ethylene copolymers. The copolymers and VTES are cross-linked via hydrolysis and condensation reactions with alkoxy groups, which greatly increase the impact strength, heat resistance, chemical resistance, creep resistance, wear resistance, and adhesive properties of the copolymers.

An extensive number of anti-stain studies have been performed, primarily modifying fibers or producing functional finishing and processing of fabrics, while adding anti-stain products into the fabric washing is rarely considered. In this study, we used PEG and VTES in different proportions to produce a series of PEG-VTES copolymers and assessed their interfacial properties and their effects on the stain resistance of cotton fabrics.

\section{Methods}

\section{Materials}

Polyethylene glycol (PEG, MW 400), vinyltriethoxysilane (97\%, VTES) (Acros Organics), and ceric ammonium nitrate (CAN) (Acros Organics) were obtained from Hayashi Pure Chemical Ind.

C.I. Direct Blue 146, Direct yellow 86, and Direct red 79 , shown below in that order in formulas 1,2 and 3 were purchased from Everlight Chemical Industrial Corp.

\section{Dyeing of Cotton Fabric}

C.I. Direct Blue 146, C.I. Direct Yellow 86, and C.I. Direct Red 79 were used for dyeing the cotton cloth. The dye (2\% o.w.f. $\mathrm{NaCl}, 1 \mathrm{~g} / \mathrm{L}$ ) was added so that the bath ratio was

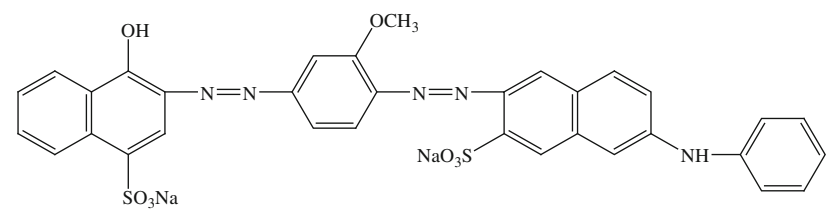

Formula 1 C.I. Direct Blue 146
1:30, and the bath was maintained at $90{ }^{\circ} \mathrm{C}$ for $30 \mathrm{~min}$, acording to scheme 1 .

\section{PEG/VTES Copolymer Preparation}

For the PEG/VTES copolymer preparation, PEG 400 was added to a $250-\mathrm{mL}$ reaction flask having four necks, a stirring rod, and a thermometer. VTES was added dropwise into the solution using a funnel. The solution was then stirred at ambient temperature for $30 \mathrm{~min}$, and $0.5 \mathrm{~g}$ of ammonium ceric nitrate was added. The temperature of the solution was then increased to $60{ }^{\circ} \mathrm{C}$ for $6 \mathrm{~h}$. The PEG/VTES product proportions indicated as PVxx are shown in Table 1.

\section{Anti-Stain Tests [15]}

\section{Test for Dye Stain Resistance}

Three kinds of cotton fabrics, each of which had been stained with C.I. Direct Blue 146, C.I. Direct Yellow 86, and C.I. Direct Red 79, were divided into two tubs. Both tubs contained dyed and white fabric, while one was supplemented with different concentrations of the copolymer solutions. These fabrics were allowed to stain at $60{ }^{\circ} \mathrm{C}$ for $30 \mathrm{~min}$. The fabrics were then dried prior to anti-stain tests using a color-difference tester.

\section{Test for Bamboo Charcoal Stain Resistance}

Bamboo charcoal powder $(10 \mathrm{~g} / \mathrm{L})$ was added to a steel cup containing white and sample fabrics and an appropriate amount of copolymer. Bamboo charcoal staining then proceeded at $60{ }^{\circ} \mathrm{C}$ for $30 \mathrm{~min}$, and the fabric was dried prior to testing whiteness value.

\section{Assay Determination and Methods}

The Fourier transform infrared/attenuated total reflection (FTIR/ATR) spectra of the finished fabrics were recorded with a Bio-Rad Digilab FTS-200 spectrometer using a MCT detector. A diamond crystal was used as an internal reflectance element. Single beam spectra were the result of 64 averaged scans. The spectral resolution was $4 \mathrm{~cm}^{-1}$. Surface tension was determined using a surface tension
Formula 2 C.I. Direct Yellow 86<smiles>Cc1cc(Nc2cc(NCCO)cc(Nc3ccc(N=Nc4cc(O)c5c(S(=O)(=O)O)cccc5c4O)c(C)c3)c2)ccc1N=Nc1cc(S(=O)(=O)O)c2cccc(S(=O)(=O)O)c2c1</smiles> 
Formula 3 C.I. Direct Red 79

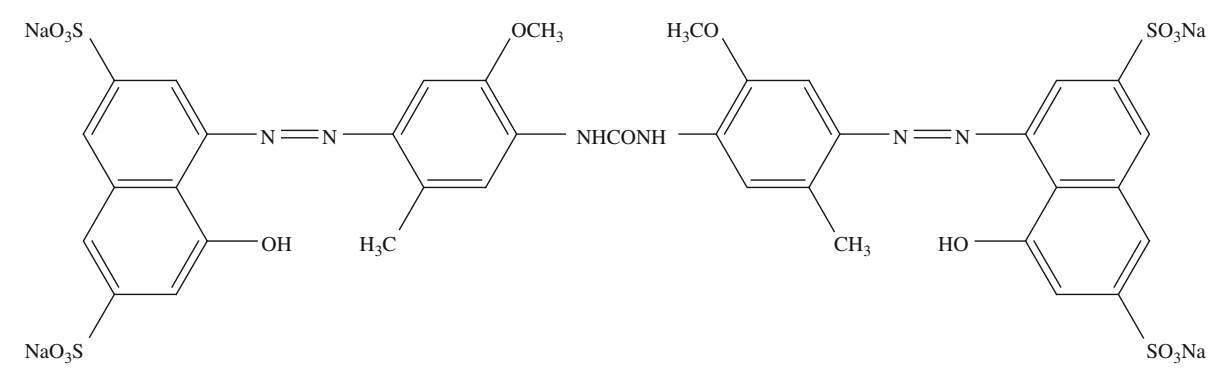

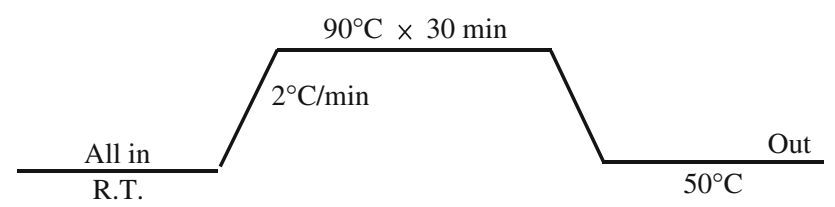

Scheme 1 Temperature programming for the dyeing process

Table 1 Code description of the investigated copolymers

\begin{tabular}{ll}
\hline PEG:VTES (mole ratio) & Code \\
\hline $2: 1$ & PV33 \\
$1: 1$ & PV50 \\
$1: 2$ & PV67 \\
\hline
\end{tabular}

measurement instrument (Kyowa CBVP-A3 surface tensiometer).

\section{Measurement of the Contact Angle}

A $1 \%$ sample solution was prepared. A static contact-angle survey meter (KSV Instrument CAM100) was used for testing. A microscope slide or a piece of fabric was placed onto the specimen platform, the sample solution was added by an injection syringe, and the liquid level was controlled at approximately $20 \mathrm{~mm}$. The solution was added dropwise to the fabric, and the data were recorded after $1 \mathrm{~min}$. This procedure was repeated four times, and the mean values were determined.

\section{Foaming Properties}

The Ross and Miles method was used for measurements $[16,17]$, and $200 \mathrm{~mL}$ of test solution was poured into a graduated tube containing $50 \mathrm{~mL}$ of test solution at the same concentration through a pore with an inside diameter of $2.9 \mathrm{~mm}$ from a height of $90 \mathrm{~cm}$. The foam height after dropping was compared with that after $5 \mathrm{~min}$, which gave the foaming height and stable foam height, respectively.

\section{Color-Difference Measurement}

The HUNTERLA color-difference meter was used for testing. Each sample cloth was tested five times in different positions, and the mean values were recorded.

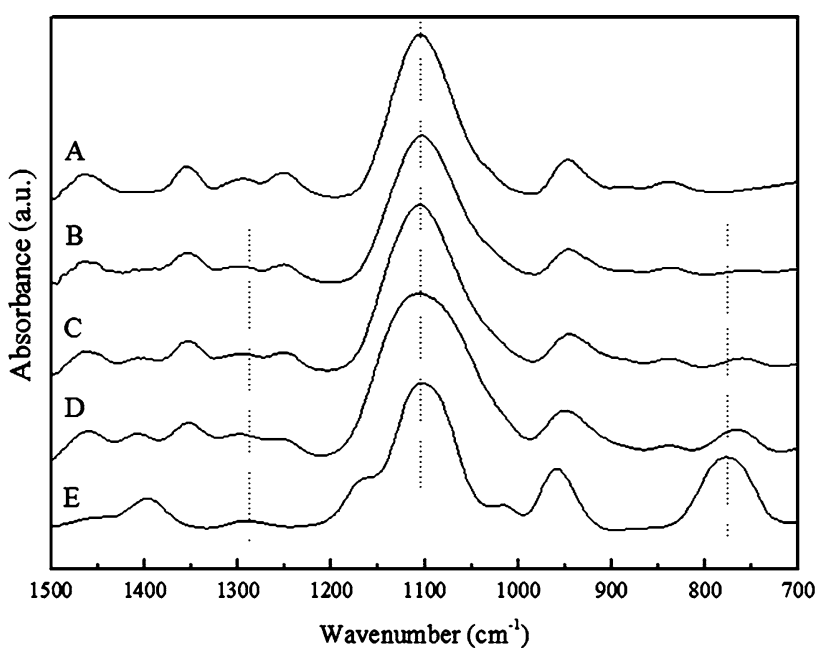

Fig. 1 IR spectra of the PEG, VTES, and copolymers. (A) PEG, (B) PV33, (C) PV50, (D) PV67, (E) VTES

\section{Results and Discussion}

Measurement of Basic Properties

\section{FT-IR Analysis of the Copolymers}

Figure 1 shows the FTIR spectra of the copolymers, PEG and VTES. Figures 1B, C, D, and E represent PEG, PV33, PV50, PV67, and VTES, respectively. As shown in Fig. 1A, the PEG characteristic absorption peaks were 1296 and $1249 \mathrm{~cm}^{-1}$, corresponding to $-\mathrm{C}-\mathrm{O}-\mathrm{C}-$, and 1,103 and $945 \mathrm{~cm}^{-1}$, corresponding to $-\mathrm{C}-\mathrm{O}-$ [18-20]. From Fig. 1E, the VTES characteristic absorption peaks were 1,101 and $775 \mathrm{~cm}^{-1}$, corresponding to $-\mathrm{Si}-\mathrm{O}-\mathrm{R}-$, $956 \mathrm{~cm}^{-1}$, corresponding to $-\mathrm{Si}-\mathrm{OEt}$, and $1,292 \mathrm{~cm}^{-1}$, corresponding to $-\mathrm{Si}-\mathrm{C}-[21,22]$. Figure $1 \mathrm{D}$ displays the PEG and VTES characteristic absorption peaks. Because PEG and VTES produced ether bonds, a wider absorption band at $1,105 \mathrm{~cm}^{-1}$ was evident, the $-\mathrm{Si}-\mathrm{C}-$ absorption peak at $1,292 \mathrm{~cm}^{-1}$ shifted to $1298 \mathrm{~cm}^{-1}$, and the $-\mathrm{C}-\mathrm{O}-\mathrm{C}$ peak at $1,249 \mathrm{~cm}^{-1}$ shifted to $1255 \mathrm{~cm}^{-1}$. Figures $1 \mathrm{~B}, \mathrm{C}$, and D show the FTIR spectra of PV33, PV50, and PV67, respectively. Increasing doses of VTES led to more obvious hydrolytic condensation. The characteristic -Si-O-Rabsorption peak at $1,091-1,105 \mathrm{~cm}^{-1}$ broadened with 
increasing doses of VTES. The -Si-O-R-absorption peak at $765 \mathrm{~cm}^{-1}$ also became more significant.

\section{Interfacial Properties of the PEG/VTES Copolymers}

The surface tension of pure water at $25^{\circ} \mathrm{C}$ was approximately $72.4 \mathrm{mN} / \mathrm{m}$. When the surfactant was added, the surface tension of the solution gradually decreased as the surfactant concentration increased. When the concentration of the surfactant was greater than the critical supermolecule concentration, the surface tension of the water remained constant. Figure 2 shows the surface tension of a series of PEG/VTES copolymers. The order of ability of the copolymers to reduce surface tension was PV67 > PV50 > PV33. The ability of the copolymers to reduce surface tension improved as the VTES content, and thus the hydrophobic group content, increased. As the number of hydrophobic groups increased, the copolymer became less soluble in water and was more likely to move towards the water surface to form an adsorption film. Therefore, PV67, with the longest hydrophobic group carbochain, displayed the best performance in the reduction of surface tension [23].

The critical micelle concentration (CMC) value of the surfactant solution is related to the free energy change when forming supermolecules, as expressed below:

$\Delta G_{\text {mic }}=2.303 \mathrm{RT}\left(\log C_{\mathrm{CMC}}-\log 55.5\right)$

where $R=1.987 \mathrm{cal} / \mathrm{mol} \mathrm{K}$ and $T=293 \mathrm{~K}\left(20^{\circ} \mathrm{C}\right)$.

The CMC values of the copolymers are shown in Fig. 2 . The values were substituted into the above equations to obtain the $\Delta G_{\text {mic }}$ of the product (Table 2). The CMC values of the products decreased as the hydrophobic chain length increased. A smaller $\Delta G_{\text {mic }}$ indicates that supermolecules are more likely to be formed. PV67 displayed the minimum CMC value, indicating that it is the most

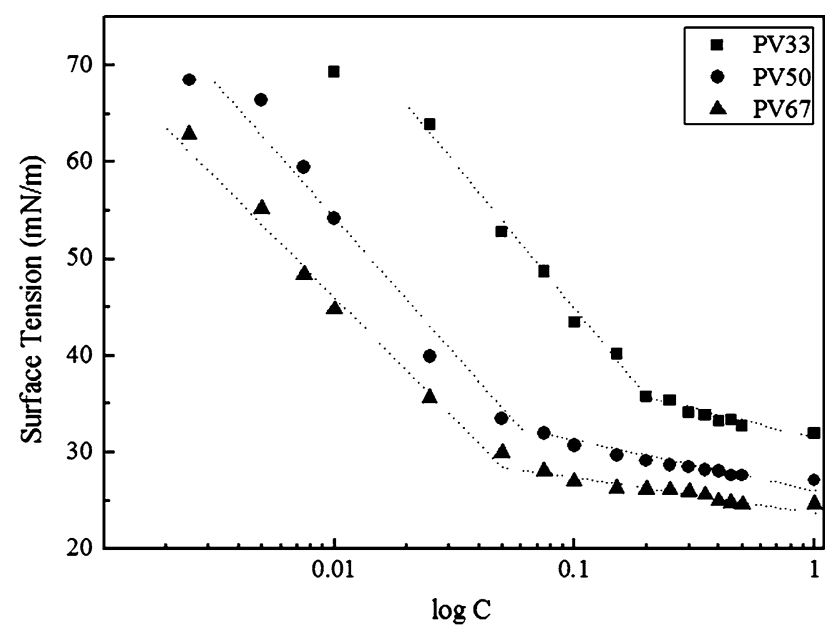

Fig. 2 Surface tension of the PEG/VTES copolymers
Table 2 CMC values and $\Delta G_{\text {mic }}$ free energy of the PEG/VTES copolymers

\begin{tabular}{lcl}
\hline Product & Log CMC $\times 10^{2}$ & $\Delta G_{\text {mic }}(\mathrm{cal} / \mathrm{mol})$ \\
\hline PV33 & 19.70 & -2074.59 \\
PV50 & 5.90 & -2259.62 \\
PV67 & 5.12 & -2270.03 \\
\hline
\end{tabular}

likely to form supermolecules, while the converse is true for PV33, which displayed the maximum CMC value.

\section{Wettability of PEG/VTES Copolymers}

A surfactant displays the ability to reduce the liquid surface tension and surface free energy, meaning it induces humidification. The wettability of the liquid or solution to a solid surface can be determined by the size of the contact angle. In this study we used glass and cotton cloth as the objects to be wetted and tested the contact angles of a series of products. As shown in Table 3, the contact angles of the products were significantly lower than the contact angle of pure water. The addition of products could reduce the surface tension of the water solution and enable the reduction in the solid surface free energy, increasing the wettability of the water solution and allowing the water to wet the cotton cloth and glass. The contact angles of the products were in the order of $\mathrm{H}_{2} \mathrm{O}>\mathrm{PV} 33>$ PV50 $>$ PV67. PV67 possessed the smallest contact angle and performed better in reducing the liquid surface tension and surface free energy, meaning it had a suitable wetting effect. As the number of hydrophobic group carbochains increased, the hydrophobicity of the products increased, the ability to reduce surface tension was enhanced, the surface tension values decreased, the solid surface free energy decreased, and the wetting affinity increased. As a result, the product was more likely to permeate and spread; thus, the measured contact angle increased as the number of hydrophobic group carbochains increased.

\section{Foamability of the PEG/VTES Copolymer}

For the solution containing surfactant, foam was produced as the hydrophobic group of the surfactant faced the interior of the bubbles, while the hydrophilic group faced the

Table 3 Contact angle of the PEG/VTES copolymers

\begin{tabular}{llr}
\hline Products & \multicolumn{2}{l}{ Contact angle $\left(^{\circ}\right)$} \\
\cline { 2 - 3 } & Glass & Cotton \\
\hline $\mathrm{H}_{2} \mathrm{O}$ & 62.20 & 116.75 \\
$\mathrm{PV} 33$ & 60.20 & 101.43 \\
PV50 & 51.33 & 83.50 \\
PV67 & 45.33 & 31.67 \\
\hline
\end{tabular}


Table 4 Foaming properties of the PEG/VTES copolymers

\begin{tabular}{lll}
\hline Copolymers & $\begin{array}{l}\text { Max. } \\
\text { height }(\mathrm{cm})\end{array}$ & $\begin{array}{l}\text { Stable foam } \\
\text { height }(\mathrm{cm})\end{array}$ \\
\hline PV33 & 0 & 0 \\
PV50 & 0 & 0 \\
PV67 & 0 & 0 \\
\hline
\end{tabular}

adsorption film of the solution phase that forms an elastic fluid film. As shown in Table 4, the foaming value of the products was $0 \mathrm{~cm}$. Compared with general surfactants, the products displayed lower foamability and foam stability. This was because the products possessed a strong ability to reduce surface tension. Therefore, they were probably adsorbed to the foam surface, with the strength of the new liquid film being low. The hydrophilic and hydrophobic groups in the product structure were disordered and unlikely to be regularly arranged around the bubbles. Therefore, the product was unlikely to form a stable elastic film at the interface because the bubbles broke rapidly after generation, and the products did not foam [24].

\section{Application of PEG/VTES Copolymers to Anti-staining}

The $K / S$ value is commonly used to measure the body surface color depth. The color strength, $K / S$, of the resultant dyeing was measured at the wave length of maximum absorbance with an automatic filter spectrophotometer and calculated with the Kubelka-Munk equation [25]:

$\frac{K}{S}=\frac{1-R^{2}}{2 R}$

where $K$ is the absorption coefficient, $S$ is the scattering coefficient, $R$ is the reflectance of the dyed samples. A larger $K / S$ value indicates a deeper color of the solid sample surface and a higher coloring matter concentration $[26,27]$. The effect of copolymer addition to the concentration of the $K / S$ value of an anti-stain-processed original white cloth is shown in Figs. 3, 4, and 5. The $K / S$ values of calico stained with blue, red, and yellow dyes were 0.3936, 0.8525 , and 1.4895 , respectively. Figure 3 shows that when PV33, PV50, and PV67 were added to the washings, the $K / S$ values of calico decreased. When the polymer concentration was $0.5 \%$, PV33 reduced the $K / S$ value of calico to 0.3125 , while PV50 and PV67 reduced it to 0.3306 and 0.3508 , respectively. When the polymer concentration was increased to $1 \%$, PV33 reduced the $K / S$ value of calico to 0.2544 , while PV50 and PV67 reduced it to 0.2693 and 0.2989 , respectively. When the polymer concentration increased to $3 \%$, PV33 reduced the $K / S$ value of calico to 0.1549 , while PV50 and PV67 reduced it to 0.1640 and 0.1740 , respectively. When the polymer concentration was increased to $5 \%$, the $K / S$ of calico did not decrease

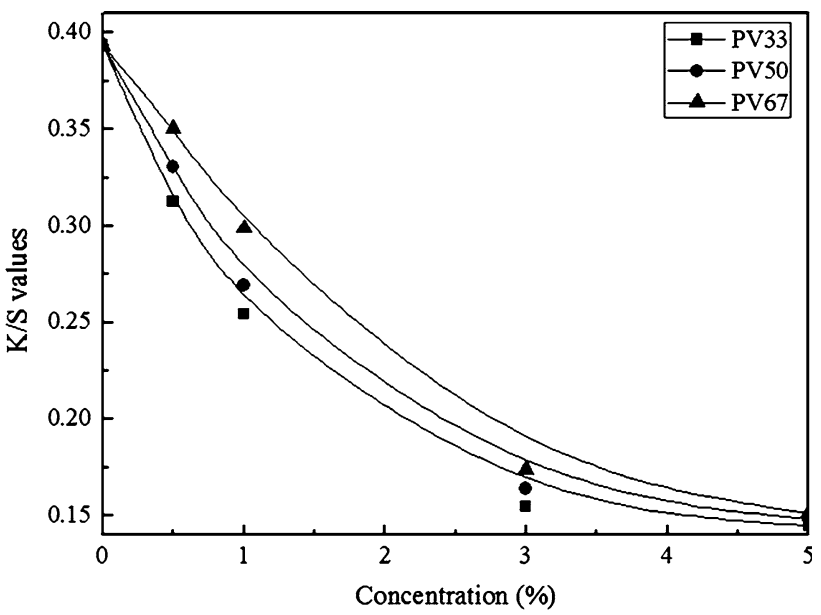

Fig. 3 Effect of the copolymer concentration on the $K / S$ value of the stained fabrics (with Blue 146 dyeing)

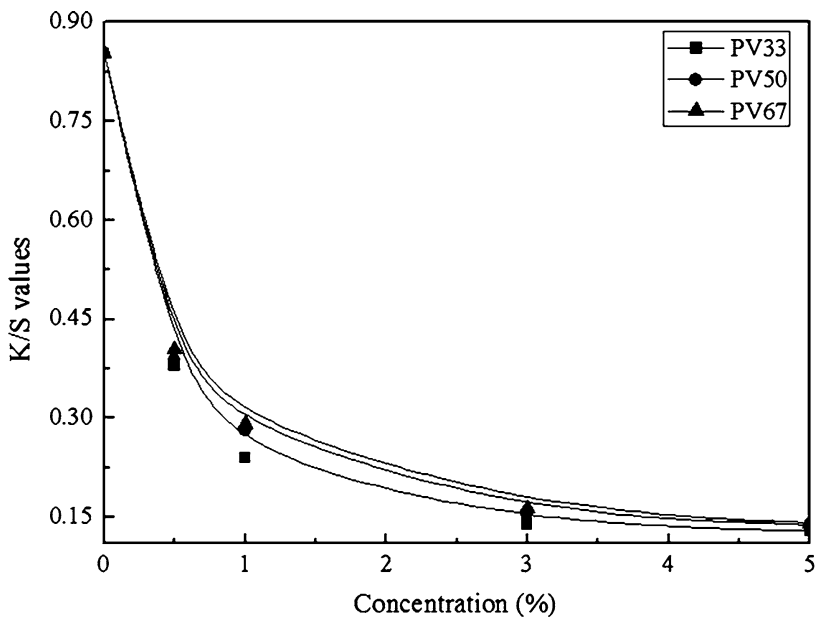

Fig. 4 Effect of the copolymer concentration on the $K / S$ value of the stained fabrics (with Red 79 dyeing)

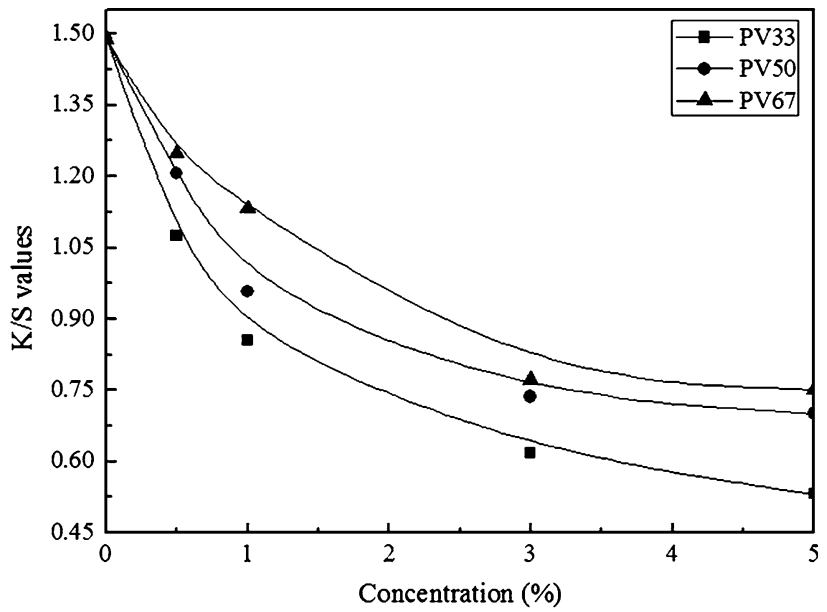

Fig. 5 Effect of the copolymer concentration on the $K / S$ value of the stained fabrics (with Yellow 86 dyeing) 
markedly; the $K / S$ values of PV33, PV50, and PV67 were $0.1450,0.1480$, and 0.1514 , respectively. This phenomenon is shown in Figs. 4 and 5. When the copolymers were added, the calico was resistant to staining as the dye wore off or dissolved from the colored goods in the presence of the copolymers. Therefore, a higher copolymer concentration indicates a lower $K / S$ value and improved stain resistance. When the copolymers collided with the dye molecules, the polymers and the $-\mathrm{OH}$ bonds of the dye structure formed hydrogen bonds, resulting in absorption and molecule enlargement. This improved stain resistance by inhibiting dye molecules from entering the fibers for dyeing. When the polymer molecules were added to the washings, the hydrophobic groups of the molecules were adsorbed into the dyes, and the hydrophilic groups arranged towards the water phase so that the dyes formed a dispersion system in water [28]. Therefore, when the hydrophobic group is longer, the dispersion or solubilization effect improves, and the adsorption effect decreases. Based on a comparison among PV33, PV50, and PV67, PV33 displayed the most favorable anti-stain effect, while the PV50 and PV67 products displayed the lowest effect. Because PV67 contains a higher level of VTES, and thus hydrophobic groups, its adsorption effect was lower than that of PV33 and PV50.

Figure 6 shows the effects of copolymer addition on the whiteness value of anti-bamboo charcoal-stain-processed calico. When $0.5 \%$ PV33, PV50, and PV67 were added to the washings, the whiteness values of the calico increased. The bamboo charcoal stain resistance improved as the addition of PV33 increased but decreased following the addition of PV50 and PV67. The addition of the copolymers made the calico resistant to the bamboo charcoal stain; the bamboo charcoal was added with the copolymers and adsorbed. The stain resistance decreased as the

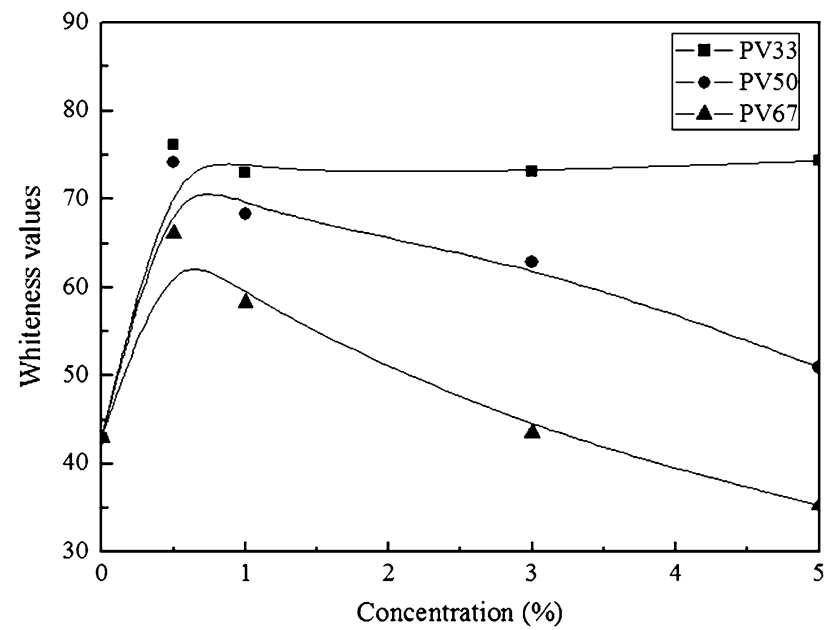

Fig. 6 Effect of the copolymer concentration on the whiteness of the stained fabrics (with bamboo charcoal powder) addition of PV50 and PV67 increased because a larger number of hydrophobic groups formed a greater number of supermolecules that solubilized or dispersed the bamboo charcoal, making it likely to enter the fiber for dyeing. A comparison of PV33, PV50, and PV67, revealed that PV33 displayed the best bamboo charcoal stain resistance, followed by PV50, while PV67 displayed the lowest performance.

\section{Conclusions}

In this study, we used PEG and VTES in different proportions to produce a series of PEG-VTES copolymers and assessed their interfacial properties and their effects on the stain resistance of cotton fabric. PEG/VTES copolymers were able to reduce water solution surface tension, with PV67 being the most efficient. The measured contact angles of the PEG/VTES copolymer water solutions were smaller than those of pure water, the wettability was good, and the copolymer solution did not foam. Thus, for practical applications, PEG/VTES copolymers confer stain resistance to cotton fabrics with PV33 displaying the most favorable stain resistance.

Open Access This article is distributed under the terms of the Creative Commons Attribution Noncommercial License which permits any noncommercial use, distribution, and reproduction in any medium, provided the original author(s) and source are credited.

\section{References}

1. Amit K, Audrey T, Marijn MCGW, Dragan J (2010) Microgelbased surface modifying system for stimuli-responsive functional finishing of cotton. Carbohydr Polym 82:1306-1314

2. Tang R, Yao F (2008) The adsorption of a syntan on nylon and its resist effectiveness towards reactive dyes. Dyes Pigments 77:665-672

3. Myung JO, Jae PK (2006) Comparison of the resist effectiveness and leveling character of a-bromoacrylamide based and 2,4dichloro-s-triazine based dye-resist agent for wool. Dyes Pigments 70:220-225

4. Qi W, Zhaokun L, Ning W, Jin L, Chengxi L (2009) The color removal of dye wastewater by magnesium chloride/red mud (MRM) from aqueous solution. J Hazard Mater 170:690-698

5. Valeria $P$, Valeria $T$, Cinzia $P$, Antonella A, Giovanni S, Giovanna CV (2008) Decolourisation and detoxification of textile effluents by fungal biosorption. Water Res 42:2911-2920

6. Tim R, Geoff M, Roger M, Poonam N (2001) Remediation of dyes in textile effluent: a critical review on current treatment technologies with a proposed alternative. Bioresour Technol $77: 247-255$

7. Inui O, Teramura Y, Iwata $\mathrm{H}$ (2010) Retention dynamics of amphiphilic polymers PEG-lipids and PVA-alkyl on the cell surface. ACS Appli Mater Interfaces 2:1514-1520

8. Lynn AD, Bryant SJ (2011) Phenotypic changes in bone marrowderived murine macrophages cultured on PEG-based hydrogels activated or not by lipopolysaccharide. Acta Biomater 7:123-132 
9. Zhao A, Zhou Q, Chen T, Weng J, WZhou S (2010) Amphiphilic PEG-based ether-anhydride terpolymers: synthesis, characterization, and micellization. J Appl Polym Sci 118:3576-3585

10. Sawant RR, Torchilin VP (2010) Polymeric micelles: polyethylene glycol-phosphatidylethanolamine (PEG-PE)-based micelles as an example. Methods Mol Biol 624:131-149

11. Kitagawa F, Kubota K, Sueyoshi K, Otsuka K (2010) One-step preparation of amino-PEG modified poly(methyl methacrylate) microchips for electrophoretic separation of biomolecules. J Pharm Biomed Anal 53:1272-1277

12. Zhi H, Li C, Bin Z, Yuan L, De YW, Yu ZW (2011) A novel efficient halogen-free flame retardant system for polycarbonate. Polym Degrad Stab 96:320-327

13. Diez M, Mela P, Seshan V, Möller M, Lensen MC (2009) Nanomolding of PEG-based hydrogels with sub-10-nm resolution. Small 5:2756-2760

14. Stahl PJ, Romano NH, Wirtz D, Yu SM (2010) PEG-based hydrogels with collagen mimetic peptide-mediated and tunable physical cross-links. Biomacromolecules 11:2336-2344

15. Huang KS, Hsiao CN, Nien YH, Lin JM (2006) Synthesis, characterization, and application of PVP/PAM copolymer. J Appl Polym Sci 99:2454-2459

16. Ross J, Miles GD (1941) An apparatus for comparison of foaming properties of soaps and detergents. Oil Soap 18:99-102

17. Japanese Industrial Standards (JIS) K 3362-90

18. Zhimei S, Runliang F, Min S, Chenyu G, Yan G, Lingbing L, Guangxi Z (2011) Curcumin-loaded PLGA-PEG-PLGA triblock copolymeric micelles: preparation, pharmacokinetics and distribution in vivo. J Colloid Interface Sci 354:116-123

19. Hong Y, Liutao L, Liqiang W, Zhiguo Z, Shiping Y (2010) Synthesis of water soluble PEG-functionalized iridium complex via click chemistry and application for cellular bioimaging. Inorg Chem Commun 13:1387-1390

20. Philip WL, Maya JJ, Rotimi ES (2010) Investigation of the degree of homogeneity and hydrogen bonding in PEG/PVP blends prepared in supercritical $\mathrm{CO}_{2}$ : comparison with ethanolcast blends and physical mixtures. J Supercrit Fluids 54:81-88

21. Rakesh KS, Shraboni D, Amarnath M (2004) Surface modified ormosil nanoparticles. J Colloid Interface Sci 277:342-346

22. Yen MS, Chen CW (2010) The synthesis of vinyltriethoxysilanemodified heteroaryl thiazole dyes and silica hybrid materials. Dyes Pigment 86:129-132

23. Lin LM, Wang CC, Chen KM, Lin PC (2009) Synthesis and physicochemical properties of casein-derived surfactants. Colloids Surf A 346:47-51
24. Wang HR, Chen KM (2006) Preparation and surface active properties of biodegradable dextrin derivative surfactants. Colloids Surf A 281:190-193

25. Garland CE (1993) In: Gultekin C (ed) Color technology in textile chemistry, 107. AATCC, Triangle Park

26. Ibrahim NA, El-Zairy WM, El-Zairy MR, Eid BM, Ghazal HA (2011) A smart approach for enhancing dyeing and functional finishing properties of cotton cellulose/polyamide- 6 fabric blend. Carbohydr Polym 83:1068-1074

27. Xue X, Li L, He J (2009) The performances of carboxymethyl chitosan in wash-off reactive dyeing. Carbohydr Polym 75:203-207

28. Chen KM, Lin LH, Wang CF, Hwang MC (2010) Interactions between new multi-anionic surfactants and direct dyes and their effects on the dyeing of cotton fabrics. Colloids Surf A $356: 46-50$

\section{Author Biographies}

Yin-Chun Chao is a doctoral student whose studies have an emphasis on the synthesis and application of surfactants at the Department of Materials Science and Engineer, National Taiwan University and Technology, Taiwan.

Shuenn-Kung Su received his Ph.D. degree from The University of Tokyo, Japan. He is a professor with an interest in the chemistry of dyestuffs at the Department of Materials Science and Engineer, National Taiwan University and Technology, Taiwan.

Ya-Wun Lin is a college student with an interest in surfactants at the Department of Materials Engineering at Kun Shan University, Taiwan.

Wan-Ting Hsu is a College student whose studies have an emphasis on colloid and interface chemistry at the Department of Materials Engineering, Kun Shan University, Taiwan.

Kuo-Shien Huang is a professor with an interest in the chemistry of surfactants and composite materials at the Department of Materials Engineering at Kun Shan University, Taiwan. 